\title{
Setting the standard: the acceptability of kitchen ventilation for the English housing stock
}

\author{
Catherine O'Leary ${ }^{\mathrm{a}}$, Benjamin Jones $^{\mathrm{a}, *}$, Sani Dimitroulopoulou ${ }^{\mathrm{b}}$, Ian P \\ Hall $^{\mathrm{c}}$ \\ ${ }^{a}$ Department of Architecture and Built Environment, University of Nottingham, \\ Nottingham, UK \\ ${ }^{b}$ Centre for Radiation, Chemical and Environmental Hazards, Public Health England, \\ Harwell Science and Innovation Campus, UK \\ ${ }^{c}$ Division of Respiratory Medicine, School of Medicine, University of Nottingham, \\ Nottingham, UK
}

\begin{abstract}
Exposure to particulate matter with diameter $\leq 2.5 \mu \mathrm{m}\left(\mathrm{PM}_{2.5}\right)$ is associated with an elevated risk of adverse health effects and cooking is a primary source of $\mathrm{PM}_{2.5}$ in non-smoking households. Therefore, it is important to investigate $\mathrm{PM}_{2.5}$ concentrations that might be found in domestic kitchens, and the appropriate ventilation mechanisms to reduce them.

Uncertainty in daily mean $\mathrm{PM}_{2.5}$ concentrations in English kitchens is predicted using a statistical model and stochastic simulation. A worst-case heating season scenario is considered where 3 meals are cooked per day and fresh air is provided by infiltration and fans.

The model predicts that $>98 \%$ of English houses are too airtight to dilute $\mathrm{PM}_{2.5}$ emissions solely by infiltration so that daily mean concentrations in kitchens are below the WHO guideline of $25 \mu \mathrm{g} / \mathrm{m}^{3}$. Therefore, controlled
\end{abstract}

\footnotetext{
${ }^{*}$ Corresponding author

Email address: benjamin.jones@nottingham.ac.uk (Benjamin Jones)
} 
ventilation is required in all kitchens. Ventilation strategies prescribed by English Building Regulations and ASHRAE 62.2 are found to be adequate for $<12 \%$ and $75 \%$ of houses, respectively, when applied during cooking. Continuing to ventilate for a further 10 minutes has a significant effect when using an intermittent strategy, increasing the centiles of compliant houses to $46 \%$ and $>98 \%$, respectively. A cooker hood is the most effective ventilation strategy when used during cooking plus 10 minutes. Standards should be amended to incorporate required combinations of airflow rates and capture efficiencies. A hood with a capture efficiency of $50 \%$ requires airflow rates of $52 \mathrm{l} / \mathrm{s}$ and $90 \mathrm{l} / \mathrm{s}$ for $\mathrm{PM}_{2.5}$ concentrations to remain below WHO guidelines in $75 \%$ and $98 \%$ of houses, respectively.

Keywords:

cooking, range hood, model, Monte Carlo, policy

\section{Introduction}

Airborne solid or liquid particles with a diameter less than $2.5 \mu \mathrm{m}$ are known as fine particulate matter $\left(\mathrm{PM}_{2.5}\right)$ [1]. When inhaled, these particles can bypass the body's defences due to their small size [1], and exposure to elevated concentrations has been associated with an increased risk of chronic and acute respiratory and cardiovascular morbidity and mortality [2, 3, 4]. The UK Air Quality Standards Regulations [5] set targets for reducing external concentrations of $\mathrm{PM}_{2.5}$, and other pollutants, to comply with EU legislation. On average, people spend $70 \%$ of time in their own houses [6, 7]. Total exposure can be considered as a function of the time spent, and the concentrations found, in different micro-environments [8] and so indoor con- 
centrations in dwellings may have a greater influence on personal exposures.

Indoor $\mathrm{PM}_{2.5}$ sources include smoking, cooking, aerosol sprays, and combustion sources, such as burning incense [9]. The best mitigation method for airborne pollutants is to remove the pollutant source. However, cooking is a common household activity where source removal is often impossible. Pollutants can be diluted by the infiltration of ambient air through adventitious openings and by purpose provided ventilation. Some ventilation systems provide source control where pollutants are removed before they can mix. Infiltration is a poor dilution mechanism because it gives low, uncontrolled airflow rates, and because it is generally desirable to eliminate it to save energy. Accordingly, purpose provided ventilation is the most appropriate mechanism. England is a country within the UK with a stock of 22.3 million dwellings [10]. Its statutory Approved Document F (ADF) [11] prescribes intermittent kitchen ventilation rates of $30 \mathrm{l} / \mathrm{s}$ adjacent to a hob (herein assumed to be through a cooker hood) or $60 \mathrm{l} / \mathrm{s}$ elsewhere, or a continuous ventilation rate of $13 \mathrm{l} / \mathrm{s}$. In new dwellings these are obligatory, whereas it is only necessary to maintain existing ventilation systems when refurbishing other dwellings. These ventilation rates were chosen to remove moisture, with the further expectation that they will dilute $\mathrm{NO}_{2}$ and $\mathrm{CO}$ emitted by gas cooking. $\mathrm{PM}_{2.5}$, and other pollutants generated during cooking, were not considered.

The lower airflow rate required by a cooker hood is based on the assumption that a significant proportion of emitted pollutants and water vapour are removed before mixing in the kitchen air. ADF does not currently require or use a performance metric for cooker hoods. A cooker hood capture efficiency 
has been defined as the percentage of an emitted pollutant extracted, either directly or during operation [12]. Capture efficiencies have not been measured in UK dwellings, but elsewhere they have been found to vary between $12 \%$ [12] and $98 \%$ [13]. The capture efficiency of a hood is a function of the airflow rate, installation height, hood capture volume, and the fraction of the stovetop covered by the hood [12, 14]. A new ASTM standard prescribes a steady-state capture efficiency test method that only considers pollutants removed before they mix with room air [15, 16].

One measure to ensure indoor air quality (IAQ) is to use a metric, such as a pollutant guideline value, an upper limit that should not be exceeded over a defined period. The World Health Organization (WHO) recommends that mean $\mathrm{PM}_{2.5}$ concentrations in ambient air are less than $10 \mu \mathrm{g} / \mathrm{m}^{3}$ per year and $25 \mu \mathrm{g} / \mathrm{m}^{3}$ per day [17]. These guidelines are also applicable to the indoor environment, as there is no convincing evidence of a difference in the hazardous nature of particulate matter from indoor and outdoor sources [18]. These values are set using toxicological and epidemiological knowledge of a pollutant's effect threshold, the concentration at which there is predicted to be a change in occupant health. Different stakeholders set different guideline values. For example, the US National Ambient Air Quality Standards require concentrations below $12 \mu \mathrm{g} / \mathrm{m}^{3}$ per year and $35 \mu \mathrm{g} / \mathrm{m}^{3}$ per day [19], and the WELL Buildings Standard sets a guideline of $15 \mu \mathrm{g} / \mathrm{m}^{3}$ [20]. These are policy and commercially driven standards, respectively, and so are more relaxed than WHO guidelines. Accordingly, the WHO guideline is used hereon for comparison. This guideline can be used to prescribe mitigation methods, such as ventilation, to ensure that it is only exceeded in a few percent of cases, 
say $5 \%$. However, the smaller the centile, the more onerous the ventilation requirements become.

Previous studies have used a range of complex modelling approaches (multi-zone representations of buildings with a large number of inputs) to estimate indoor concentrations [21], or exposures [22, 23, 24, 25, 7], of $\mathrm{PM}_{2.5}$ [22, 23, 25, 21] and other pollutants [26, 27, 28, 7, 24, 25], for all [23, 24, 25] or part [7, 22, 21] of the English housing stock. They generally do this by creating archetypal rooms or whole houses that are simulated either deterministically (with a single set of input parameters), or probabilistically (varying the input parameters within a range of known values). The predictions are then extrapolated to the housing stock scale. This approach is useful for predicting concentrations or exposures that would be difficult and time consuming to measure in-situ. Additionally, these models have been used to predict concentrations or exposures for future scenarios [22, 23, 24, 25], which is useful for testing the potential impacts of retrofit policies. However, these models frequently simplify occupancy behaviour and cooking emissions to a single pattern and emission rate. $\mathrm{PM}_{2.5}$ emissions from cooking are often simplified to a single distribution of $1.6 \pm 0.6 \mathrm{mg} / \mathrm{min}$ [28, 22, 23], although emissions reported in the literature have greater variability. Finally, the complex models described here can provide good estimates of indoor pollutant concentrations or exposures, but the significant time and computational power they require limits their ability to test many different scenarios. This makes them useful for testing the efficacy of existing or proposed regulations, but not for searching for optimal solutions to a problem, such as identifying appropriate ventilation rates for domestic kitchens. 
Alternatively, Salthammer 8] proposes a statistical approach to generate a probability density function (PDF) of pollutant concentrations using a simple mass-balance model and Monte-Carlo sampling. The model assumes that the pollutant is well mixed throughout the room once released, and that the environmental conditions remain constant. The steady-state concentration is then predicted as a function of the emission rate, decay rate (a combination of ventilation and deposition for $\mathrm{PM}_{2.5}$ ), and room volume. If each input is considered to be a random variable with a known distribution, sampling from these distributions and performing multiple calculations gives a PDF of steady-state concentrations. This method is useful for pollutants that have a constant source, such as formaldehyde emitted from building materials [8]. For intermittent sources, such as cooking, this method can also be used to predict steady-state concentrations. However, the predicted concentrations are not useful for setting ventilation rates required to mitigate exposure as its unlikely the steady-state concentration will be reached [29]. Additionally, the guidelines are based on mean average concentrations over time, so a model should predict mean concentrations over the same time period.

This paper seeks to provide a rudimentary assessment of the English housing stock and the suitability of the English Building Regulations given in $\mathrm{ADF}$ for removing $\mathrm{PM}_{2.5}$ emitted by cooking using a mathematical model following Salthammer's method. 24-hour mean concentrations in kitchens are predicted for different ventilation strategies and stock scenarios using Monte-Carlo sampling, informed by the English Housing Survey (EHS) [10]. The predictions are used to consider the ventilation strategies, cooker hood 
capture efficiencies, and ventilation rates that keep $\mathrm{PM}_{2.5}$ concentrations below health-based guidelines in 50\%, $75 \%$ and $98 \%$ of English kitchens, and thus minimise population exposure to them.

\section{Methods}

The method uses a bespoke MATLAB code ${ }^{1}$ to run Monte-Carlo simulations to predict 24-hour mean concentrations in a representative sample of English kitchens, based initially on the method outlined by Salthammer [8].

\subsection{Model}

We apply a widely used mass-balance model of a single zone developed by Ott et al. [30] as a basis of our calculations. Ott's model is similar in form to Equation 1 and is frequently used to predict the concentration at the end of a time period $t$, or to estimate emission rates from measured temporal concentrations [30, 31]. The pollutant concentration, $C(t)\left(\mu \mathrm{g} / \mathrm{m}^{3}\right)$, as a function of time, $t$ (hours), is given by

$$
C(t)=C_{s s}+\left[C(0)-C_{s s}\right] e^{-\left(\lambda_{T}+k\right) t}
$$

where $C(0)\left(\mu \mathrm{g} / \mathrm{m}^{3}\right)$ is the concentration when $t=0$ hours, and $C_{s s}\left(\mu \mathrm{g} / \mathrm{m}^{3}\right)$ is the theoretical steady-state concentration. The pollutant concentration tends towards $C_{s s}$ over time when conditions are constant, and is given by

$$
C_{s s}=\frac{\lambda_{T} P C_{a}}{\left(\lambda_{T}+k\right)}+\frac{(1-\eta) G}{\left(\lambda_{T}+k\right) V}
$$

\footnotetext{
${ }^{1}$ https://www.researchgate.net/project/Predicting-24-hour-mean-PM25concentrations-in-stocks-of-houses
} 
Here, $C_{s s}$ is a function of the total ventilation rate, $\lambda_{T}\left(\mathrm{~h}^{-1}\right)$, the deposition rate, $k\left(\mathrm{~h}^{-1}\right)$, the ambient concentration, $C_{a}\left(\mu \mathrm{g} / \mathrm{m}^{3}\right)$, the dimensionless penetration coefficient, $P$, the source emission rate, $G(\mu \mathrm{g} / \mathrm{h})$, and the dimensionless cooker hood capture efficiency, $\eta$. This model assumes that emitted pollutants are instantaneously fully mixed throughout the room volume.

The mean concentration, $\overline{C(t)}\left(\mu \mathrm{g} / \mathrm{m}^{3}\right)$, between times $t=0$ and $t=t$, is found by integrating Equation 1 between these limits and dividing by the time period of interest, $t$.

$$
\overline{C(t)}=C_{s s}-\frac{C(t)-C(0)}{\left(\lambda_{T}+k\right) t}
$$

All three equations assume constant conditions over time [30]. Therefore, to predict the mean average concentration over a significant period of time, $T$ (hours), such as a day, it is divided into $j$ distinct sub-periods where the total time is equal to the sum of the durations of each sub-period, so $T=\sum_{i=1}^{j} t_{i}$. Each sub-period corresponds to a change in the emission or ventilation rates so that the final concentration of each sub-period is also the initial concentration of the next. The overall mean concentration over $T$ is then calculated from the weighted mean, $\overline{C\left(t_{i}\right)}$, for each sub-period where

$$
\overline{C(T)}=\frac{\sum_{i=1}^{j}\left(\overline{C\left(t_{i}\right)} \cdot t_{i}\right)}{T}
$$

\subsection{Stocks, Strategies, and Scenarios}

Two housing stocks are considered: a stock of new build houses, and the existing housing stock that includes new houses. This reflects the separation in $\mathrm{ADF}$ of requirements for work to existing dwellings and new houses and al- 
lows the differences in kitchen volume (see Section 2.3.1) and air permeability (see Section 2.3.2) between the two stocks to be assessed.

Six ventilation strategies are tested within the contexts of two scenarios. The strategies are chosen because they are either specified in ADF, or because ADF implicitly allows them.

The first scenario considers the existing requirements of the building regulations to assess their suitability. The requirements for new kitchens are assessed for both stocks, because existing dwellings only have to maintain an existing ventilation strategy whose details are unknown. The six ventilation strategies are simulated for each stock, which are outlined in Table 1 and Figure 1. There is currently no capture efficiency requirement in ADF, however the $50 \%$ reduction in the required ventilation rate through a cooker hood from the room extract fan implies a capture efficiency of $50 \%$, hence this value is used for the initial assessment. We also investigate the potential benefits of continuing intermittent ventilation for an additional 10 minutes after the end of the cooking period. The appropriateness of this time is discussed in Section 4.3. Predicted concentrations are aggregated to a daily mean concentration so that they can be directly compared to the WHO 24-hour mean guideline of $25 \mu \mathrm{g} / \mathrm{m}^{3}$ [17].

The second scenario considers the fan airflow rates required to minimize occupant exposures to $\mathrm{PM}_{2.5}$. Here, the model is run for a range of capture efficiencies (0-100\%) and ventilation rates (0-800 l/s). For each combination of capture efficiency and fan airflow rate, we predict the percentage of kitchens in which the daily mean concentration remains below the WHO 24-hour mean guideline. These percentages are then interpolated to develop 
curves that show the combination of ventilation rate and capture efficiency required for the daily mean concentration to remain below the guideline value in $2 \%, 25 \%, 50 \%, 75 \%$ and $98 \%$ of kitchens.

\subsection{Model Inputs}

The flow rate and capture efficiency of the modelled ventilation strategy are independent variables, and so these inputs are fixed. All other inputs are modelled probabilistically, sampled from appropriate distributions. Empirical distributions are fitted using piecewise cubic hermite interpolating polynomials [32].

\subsubsection{Kitchen Volume, $V$}

The English housing stock comprises 22.3 million dwellings, of which a statistically representative sample of 16,150 dwellings is documented by the 2009 English Housing Survey (EHS) [10]. Each house is weighted so that the sum of the weights equals $22.3 \mathrm{~m}$. Although the 2009 survey is not the most recent, it is selected because it was previously used to derive distributions of infiltration rates; see Section 2.3.2. The kitchen volume of each surveyed house is the product of the reported height, width, and depth. These volumes, and the corresponding weight of each sampled house, were used to create two empirical cumulative distribution functions (CDFs), from which volumes are sampled. The first CDF is for the entire housing stock, and the second for houses built post 2002. This year is the newest age bin given by the EHS. Entries with no recorded kitchen dimension data were ignored, the remaining data sets represent $99.75 \%$ of the entire English housing stock, and $99.65 \%$ of the post 2002 housing stock. Figure 2 shows volume distributions 
for both stocks. Neither distribution is normally distributed, and both are positively skewed. The mean and standard deviation are $26.5 \mathrm{~m}^{3}$ and $13.8 \mathrm{~m}^{3}$ for the existing stock, and $30.6 \mathrm{~m}^{3}$ and $18.6 \mathrm{~m}^{3}$ for new houses. This indicates that there is a trend towards larger kitchens in new English houses.

\subsubsection{Ventilation Rate, $\lambda_{T}$}

Airflow in houses comprises ventilation through purpose-provided openings, infiltration and exfiltration through adventitious openings, and airflow through mechanical systems. Six ventilation strategies are considered initially; see Section 2.2 and Table 1. All assume that purpose--provided openings are sealed representing limiting conditions during the heating season. Infiltration is assumed to occur in all scenarios, and is considered to be a function of a measurement of air permeability, the airflow rate through adventitious openings at a pressure differential of $50 \mathrm{~Pa}$ normalized by dwelling surface area. Distributions of hourly infiltration rates in English houses are used in order to explore as much infiltration variability as possible. They were generated using DOMVENT3D, an open source $2^{2}$ implicit model of infiltration and exfiltration through any number of façades [33, 34, 35, 36, 32]. It assumes that all façades are uniformly porous and that the pressure distribution over a vertical surface is linear. Further assumptions, merits, limitations, and the corroboration of its predictions are discussed widely by Jones et al. [35, 36], and an analysis of the sensitivity of its predictions to its inputs has been undertaken [32].

\footnotetext{
${ }^{2}$ The code is available under a creative commons license from DOI: 10.13140/RG.2.2.30311.39844
} 
The majority of English houses share a party wall with another house and, because their permeability is unknown, they were considered to be either impermeable or as permeable as other walls with equal probability.

All inputs to DOMVENT3D are identical to those described by Jones et al. [32], except for the distributions of air permeability. For pre-2002 houses, the Stephen distribution [37] is used, comprising measurements made in 384 UK dwellings built before 2000. For post-2002 houses, a distribution is applied derived from measurements tested under the Air Tightness Testing and Measurement Association (ATTMA) scheme in 144,024 new UK houses between 2015 and 2016, which has been evaluated previously et al. [38, 39].

In any house with its purpose-provided openings closed and mechanical systems switched off, the total airflow rate, $\lambda_{T}$, is equal to the infiltration rate, $\lambda_{N}\left(\mathrm{~h}^{-1}\right)$. When a mechanical system is switched on, all make-up air is assumed to occur via infiltration or exfiltration. Generally, in a leaky house with a high value of air permeability, a small mechanical extract flow rate, $\lambda_{M}\left(\mathrm{~h}^{-1}\right)$, creates a small reduction in the internal air pressure that it increases the infiltration rate and decreases the exfiltration rate by the same magnitude. Therefore, the change to the total airflow rate attributable to the mechanical system is equal to $\lambda_{M} / 2$, so that $\lambda_{T}=\lambda_{N}+\lambda_{M} / 2$. In an airtight house, a small extract flow creates a much larger reduction in indoor air pressure that eliminates exfiltration so that $\lambda_{T}=\lambda_{M}$. These limits have been discussed previously [40, 41, 35] and the transition between them in UK houses is shown to be well modelled by superposition using a power law [35. However, the exponent is unique for every house and so, in the absence of knowledge, a high exponent is advised. Then, the model of total airflow rate 
reduces to

$$
\lambda_{T}=\max \left\{\lambda_{N}+\frac{\lambda_{M}}{2}, \lambda_{M}\right\}
$$

when it is known as the half-fan model.

When comparing the differences in hourly infiltration rates in US houses predicted by a numerical airflow mass-balance model that gives a physically correct solution and the half-fan model, the root mean square error was found to be $<5 \%$ [41].

The half-fan model has been shown to be less accurate than an exponential relationship between $\lambda_{M}$ and $\lambda_{N}$. However, the exponential model not been evaluated for the English stock whereas the half-fan model has. The half-fan model model is explicit and, therefore, computationally inexpensive so it can be used to explore a range of ventilation scenarios in a short period of time.

\subsubsection{Penetration Coefficient, $P$}

The penetration coefficient is a non-dimensional parameter between 0 and 1 that represents the filtering effect of the building envelope [30]. The value of $P$ depends on the size distribution of the aerosol and the flow characteristics through an airflow path [42], where $P=1$ for airflow through large openings, such as open windows, and $P<1$ for other airflow paths [30]. $P$ has been found to vary between 0.7 and 0.9 with particle size [30], but previous models have treated $\mathrm{PM}_{2.5}$ as an homogeneous pollutant and modelled $P=0.8$ for the heating season conditions [43] considered here. Therefore, $P$ is considered uniformly distributed between 0.7 and 0.9 . 


\subsubsection{Capture Efficiency, $\eta$}

Two types of cooking are considered: foods cooked on a stove and those cooked elsewhere. For the general extract ventilation scenarios (B-D), the cooking location is unimportant because it is assumed that all emitted $\mathrm{PM}_{2.5}$ fully mix within the space so that $\eta=0$. When meals are not cooked on a hob the same mixing and capture efficiency assumptions can be made; see Section 2.3.8. However, when a cooker hood is used and a meal is cooked on a hob, the proportion of emitted $\mathrm{PM}_{2.5}$ captured by the cooker hood before they can mix in the kitchen is given by $\eta$; see Equation 2 . There are no typical values of $\eta$ for English devices given in the literature. Accordingly, an initial value of $50 \%$ is assumed (see Section 3.2.3) for the initial assessment of the building regulations, and then values between 0-100\% are tested.

\subsubsection{Deposition Rate, $k$}

A deposition rate of $0.39 \pm 0.16 \mathrm{~h}^{-1}$ from Ozkaynak et al. [44 is used. It is derived from 1780 personal monitoring measurements in non-smoking residences, and has been used by other $\mathrm{PM}_{2.5}$ modelling studies [28, 25, 21, 24]. Deposition rates are assumed to be normally distributed with the distribution truncated between $0 \mathrm{~h}^{-1}$ and $0.78 \mathrm{~h}^{-1}$, for a positive distribution with the same mean.

\subsubsection{Ambient Concentration, $C_{a}$}

The ambient, or external, $\mathrm{PM}_{2.5}$ concentration is assumed to be uniformly distributed between $8.6 \mu \mathrm{g} / \mathrm{m}^{3}$ and $14.6 \mu \mathrm{g} / \mathrm{m}^{3}$. These concentrations are reported for London [43], however there is a precedent of applying this data to the entire housing stock [23]. 


\subsubsection{Initial Concentration, $C(0)$}

The initial concentration is assumed to equal the background indoor concentration, which is also the steady-state concentration in the absence of internal sources

$$
C(0)=C_{b}=C_{s s}=\frac{\lambda_{T} P C_{a}}{\left(\lambda_{T}+k\right)}
$$

$C(0)$ is calculated using Equation 6 for $\lambda_{T}$ at the start of the day. If the concentration at the end of the total time period, $C(T)$, is significantly different from that at the beginning, $C(0)$, the calculations are repeated with $C(0)=C(T)$ and the process continues until $C(T)-C(0) \leq 1 \%$. The final value of $C(0)$ is recorded as an input.

\subsubsection{Cooking Frequency and Emission Rate, $G$}

The total time period is one day, so $T=24$ hours, and 3 meals are cooked per day. This is to simulate a significant, but not extreme, emissions profile, such as a weekend where occupants are at home all day and cook multiple times. Similar emission profiles have been considered by other analyses of IAQ [21, 25].

The first meal is always the toasting of bread, representing breakfast. Emission rates are sampled from an empirical CDF with $\mu=0.22 \mathrm{mg} / \mathrm{min}$ and $\sigma=0.065 \mathrm{mg} / \mathrm{min}$, derived from 26 repetitions of toasting bread in an

outdoor chamber [45]. The emission rates have been recalculated using a calibration factor of 0.64 obtained using subsequent gravimetric sampling (see [46]). The meal duration was assumed to be normally distributed with $\mu=3.8$ minutes and $\sigma=0.9$ minutes, following O'Leary et al. [45]. 
The other meals are considered typical of those cooked on a stove top in Northern Europe and their emission rates and cooking durations are reported by O'Leary et al. [47.

Each of the meals is assumed equally likely to be cooked. First, the meal type is sampled, and then the emission rate and cooking duration are sampled from their corresponding normal distributions in Table 2.

The cooking schedule was made highly variable to account for a lack of data describing cooking behaviour in the UK. The relative importance of this input is interrogated by a sensitivity analysis; see Section 2.6. The start time of each meal is assumed to be uniformly distributed between 0600-1000 for breakfast, 1000-1400 for lunch, and 1600-2000 for dinner.

To maximise the decay period after the final cooking event, the simulation start time $(t=0)$ always coincides with the beginning of the breakfast cooking period.

\subsection{Example Strategies}

To help explain how the model works, Figure 3 shows predicted concentrations over time for ventilation strategies A, C, and F (see Table 1) in the same kitchen. All other inputs are identical and are given in Table 3. All of the inputs are arbitrary and are only for illustrative purposes. The daily mean

$\mathrm{PM}_{2.5}$ concentrations, $\overline{C(T)}$, calculated using Equations 14 , are $214 \mu \mathrm{g} / \mathrm{m}^{3}$, $73.3 \mu \mathrm{g} / \mathrm{m}^{3}$ and $38.1 \mu \mathrm{g} / \mathrm{m}^{3}$ for strategies $\mathrm{A}, \mathrm{C}$, and $\mathrm{F}$, respectively.

\subsection{Sampling Method}

The sampling method follows that described by Das et al. [21] and Jones et al. [32]. There are 17 input variables required to calculate $\overline{C(T)}$, which 
are sampled in sets of 100 using a Latin Hypercube. Each set of samples is applied to predict $\overline{C(T)}$; see Section 2.1. The total sample size increases incrementally by the set size. After each set of predictions is made, the overall mean $(\mu)$ and standard deviation $(\sigma)$ of $\overline{C(T)}$ for all sets of samples are calculated. When the change in $\mu$ and $\sigma$ from the addition of one set of samples to the next is $\leq 0.01 \%$ the total number of samples is deemed adequate.

\subsection{Sensitivity Analysis}

A sensitivity analysis is used to test the dependence of $\overline{C(T)}$ on the model inputs. Here we follow the method of Jones et al. 32 and a full description is found in the reference. The method tests for linear (Kendell's tau, Pearson's product moment, linear regression), monotonic (Spearman's rank correlation coefficient, rank-transformed standardized variables) and non-monotonic (Kolmogorov-Smirnov, Kruskal-Wallis) relationships between inputs and outputs. All inputs are ranked according to the magnitude of the regression coefficient.

A fundamental requirement is that all tested inputs are independent of one another. Therefore, the emission rates, $G$, and source durations are combined as a product to form a single input variable, the total source strength, $g$, which is the total mass of $\mathrm{PM}_{2.5}$ emitted per day. The tested input variables are $V, \lambda_{N}, k, C_{a}, P, C(0), g$, and the mean average time between cooking events. The sensitivity of $\overline{C(T)}$ to the number of emission periods and to the background concentration is not tested because it is assumed to be constant; see Section 2.3 . 


\section{Results}

\subsection{Existing Regulations}

Figure 4 and Table 4 show the predicted $\mathrm{PM}_{2.5}$ concentrations for ventilation strategies A-F (see Table 1) for both the existing stock (Figure 4a) and new houses (Figure 4b). When infiltration is the only source of fresh air (strategy A), the predicted daily mean $\mathrm{PM}_{2.5}$ concentrations are at, or below, the WHO guideline of $25 \mu \mathrm{g} / \mathrm{m}^{3}$ in $0.3 \%$ of existing and new kitchens. This improves when $13 \mathrm{l} / \mathrm{s}$ of continuous mechanical ventilation is used (strategy B) to $1.6 \%$ of existing kitchens and $2.0 \%$ of new kitchens. When $60 \mathrm{l} / \mathrm{s}$ general extract is used during cooking (strategy C), $5.6 \%$ of existing kitchens and $4.3 \%$ of new kitchens meet the WHO guideline. The best performance occurs when using a cooker hood with an airflow rate of $30 \mathrm{l} / \mathrm{s}$ and a capture efficiency of $50 \%$ (strategy E), where $12 \%$ of existing, and $10 \%$ of new, kitchens are below the WHO guideline. The predictions highlight that halving a general extract airflow rate and assuming a 50\% capture efficiency will not give the same results. Overall, the existing requirements perform poorly, especially in new houses, where $\leq 10 \%$ of kitchens are below the WHO guideline. This is because new houses are more airtight.

However, continuing an intermittent ventilation strategy for 10 minutes after cooking ends is predicted to increase the percentage of kitchens below the WHO guideline. When $60 \mathrm{l} / \mathrm{s}$ general extract (strategy D), $46 \%$ of existing kitchens or $41 \%$ of new kitchens are predicted to be below the WHO guideline. And when using $30 \mathrm{l} / \mathrm{s}$ extract through a cooker hood with $50 \%$ capture efficiency (strategy F), 33\% of existing, and $31 \%$ of new, kitchens are below the WHO guideline. Here, the general extract strategy achieves lower 
$\mathrm{PM}_{2.5}$ concentrations because the ventilation rate is higher and the capture efficiency does not apply after cooking has ended.

The distributions of data are shown by the shaded violins in Figure 4 , and are similar in shape for all of the intermittent ventilation scenarios (Strategies $\mathrm{C}-\mathrm{D})$. There is greater variability, particularly for higher concentrations, in the predictions for existing kitchens than new. Strategy A (infiltration only) has the greatest variance, whereas Strategy B (constant extract) has the least and is bi-modal.

\subsection{Required Ventilation Rates}

\subsubsection{Constant General Extract}

Figures $5 \mathrm{a}$ and $5 \mathrm{~b}$ show the predicted concentrations at a range of airflow rates for constant mechanical extract ventilation. For $98 \%$ of kitchens to remain below the $25 \mu \mathrm{g} / \mathrm{m}^{3} 24$-hour mean guideline, they predict a required ventilation rate of $97 \mathrm{l} / \mathrm{s}\left(\right.$ or $24 \mathrm{~h}^{-1}$ ) for the existing housing stock or $96 \mathrm{l} / \mathrm{s}$ (or $25 \mathrm{~h}^{-1}$ ) for new houses. New houses are more airtight and so they generally require a higher fan airflow rate. The ventilation rates required for other percentages of kitchens to remain below the guideline concentration are included in Table 5. The predicted constant ventilation rate for $75 \%$ houses (new or existing) to remain below the guideline, at 61-62 l/s, is almost five times the current required constant ventilation rate required by $\mathrm{ADF}$.

\subsubsection{Intermittent General Extract}

When using intermittent extract ventilation away from a stove (not through a cooker hood), the ventilation rates required for $98 \%$ of kitchens to remain below the WHO guideline are predicted to be $627 \mathrm{l} / \mathrm{s}\left(131 \mathrm{~h}^{-1}\right)$ for exist- 
ing kitchens and $726 \mathrm{l} / \mathrm{s}\left(154 \mathrm{~h}^{-1}\right)$ for new. See Table 5 for other centiles. The predicted ventilation rates for both $75 \%$ and $98 \%$ kitchens to comply are considerably higher than the existing requirements, and high air change rates can cause additional problems, such as increased energy demand and pressure differentials [35].

Continuing ventilation for 10 minutes after cooking is also beneficial here. Figures $5 \mathrm{c}$ and $5 \mathrm{~d}$ show the predicted concentrations for a range of ventilation rates. When ventilation continues after cooking, the mean concentrations drop considerably for the same flow rate. Here, for $98 \%$ kitchens to remain below the WHO guideline, the predicted ventilation rate is $119 \mathrm{l} / \mathrm{s}\left(22 \mathrm{~h}^{-1}\right)$ for existing houses, and $137 \mathrm{l} / \mathrm{s}\left(23 \mathrm{~h}^{-1}\right)$ for new houses. These ventilation rates are high when compared to those specified by ADF. However, the 75th centile ventilation rates of $78 \mathrm{l} / \mathrm{s}$ for existing kitchens, and $83 \mathrm{l} / \mathrm{s}$ for new, are closer to the required $60 \mathrm{l} / \mathrm{s}$; see Table 5 .

\subsubsection{Cooker Hood}

When air is extracted through a cooker hood, its capture efficiency must also be considered. This is where the percentage of kitchens below the guideline is useful, to produce a plot relating the required capture efficiency and flow rate for each centile of kitchens. Figure 6 shows the relationships between airflow rate and capture efficiency for the existing housing stock and new dwellings. The capture efficiency of cooker hoods installed in UK dwellings is unknown, and cooker hood capture efficiencies have been shown to increase with the flow rate [14, 12]. However, for the 50\% capture efficiency implicitly assumed by ADF, the predicted ventilation rates needs to be at least $91 \mathrm{l} / \mathrm{s}, 143 \mathrm{l} / \mathrm{s}$ or $316 \mathrm{l} / \mathrm{s}$ for $50 \%, 75 \%$, or $98 \%$ of existing kitchens to comply, 
respectively, if the hood is switched on only during cooking; see Figure 6a. In new houses, the corresponding minimum ventilation rates required are $103 \mathrm{l} / \mathrm{s}, 161 \mathrm{l} / \mathrm{s}$ and $366 \mathrm{l} / \mathrm{s}$; see Figure 6b.

Continuing to run the cooker hood after cooking ends leads to lower flow rates and/or capture efficiencies, indicated by the dashed lines in Figure 6 . Assuming the same $50 \%$ capture efficiency, the minimum required flow rates for $50 \%, 75 \%$ or $98 \%$ kitchens to comply would be $37 \mathrm{l} / \mathrm{s}, 49 \mathrm{l} / \mathrm{s}$ or $78 \mathrm{l} / \mathrm{s}$ in existing houses (Figure 6a) and $39 \mathrm{l} / \mathrm{s}, 52 \mathrm{l} / \mathrm{s}$ or $90 \mathrm{l} / \mathrm{s}$ in new houses (Figure $6 \mathrm{~b}$.

These theoretical combinations of capture efficiency and flow rate have limited use if they are not compared to the measured performance of installed cooker hoods. Figure 6 could be used as a tool by combining it with empirical curves that relate measured capture efficiency, $\eta_{\text {measured }}$, and airflow rate for real cooker hoods. An example is given in Figure 7. The two curves labelled Example $A$ and Example $B$ are produced by fitting empirical data to the equation $\eta=\eta_{\max }\left(1-e^{-\alpha \lambda_{M}}\right)$, where $\eta_{\max }=100 \%$ and $\alpha$ is a constant equal to the magnitude of the gradient from the log-linear regression of $\eta_{\text {max }}-\eta_{\text {measured }}$. The data for Example $A$ is obtained from measurements of the performance of a single hood [48], whereas Example $B$ comprises the combined data for 7 hoods located at multiple mounting heights [49]. These examples show how their intersections with the efficiency-airflow rate curves could be used to set the hood's airflow rate. For example, if a cooker hood with the same properties as Example $A$ is installed with an airflow rate of $\geq 51 \mathrm{l} / \mathrm{s}$, its corresponding capture efficiency of $\geq 82 \%$ would keep $\mathrm{PM}_{2.5}$ concentrations below the WHO guideline in $75 \%$ of new kitchens when used 
just during cooking.

\subsection{Sensitivity Analysis}

Table 6 shows the results for the sensitivity analysis described in Section 2.6. It is used to determine the relative importance of independent input variables, where a rank of 1 indicates the most important input variable. The total source strength, $g$, is ranked the most influential by all tests. The least important input varies between tests, but the ambient concentration, penetration coefficient and average time between meals are consistently ranked lowest. This is important because these inputs involved the most assumptions. The relationships between these inputs and outputs were statistically significant $(p \leq 0.05)$ for most high ranked inputs across all tests. Lower ranked inputs were also often non-significant; see Table 6. The lower ranking of the time between meals means the model could be simplified by fixing this input with the penalty of removing the capability to test the effect of continuing ventilation after cooking ends.

\section{Discussion}

\subsection{Drawbacks}

We compare predicted 24-hour mean $\mathrm{PM}_{2.5}$ concentrations to the WHO guideline, which assumes that occupants spend all of their time in the kitchen. This is generally not the case, and so we focus on $\mathrm{PM}_{2.5}$ exposures experienced by cooks and others who may consistently occupy a kitchen, such as young children. In dwellings with open plan kitchens, both non-cooks and cooks are likely to be exposed to elevated concentrations for longer. 
Open plan kitchens are included in the volume distributions (see Figure 2), however the model does not distinguish between open plan and enclosed kitchens. A multi-zone model coupled with occupancy patterns, similar to the approaches undertaken by [22, 25, 7], may give a more realistic estimation of exposure for different types of occupant. However, this would require the use of appropriate archetypes and occupancy patterns, and need more computational time, although it should be investigated in the future. This study is not intended to investigate personal exposures in that way. Instead, the intention was to perform an investigation into the $\mathrm{PM}_{2.5}$ concentrations that might be found in domestic kitchens, and the appropriate ventilation mechanisms to reduce them. Comparing to the WHO's 24-hour guideline provides a rudimentary assessment of acute exposure. In order to consider the chronic impact of indoor $\mathrm{PM}_{2.5}$ concentrations from cooking sources a model is required whose predictions can be compared to the WHO annual mean guideline of $10 \mu \mathrm{g} / \mathrm{m}^{3}$. This requires a more complex model that considers multiple cooking and occupancy patterns, similar to [23, 25, 7], and should also consider seasonal variations in ventilation use. We currently only consider worst-case heating season conditions where infiltration is the only source of natural driven airflow. However, occupants are more likely to open windows in summer months as air temperatures increase [50], thereby increasing the total ventilation rate. In these circumstances, it is important to understand how naturally driven ventilation through purpose-provided openings and kitchen fans affect one-another. 


\subsection{Context}

The predicted 24-hour mean concentrations given in Table 4 can be compared to in-situ measurements. For example, 24-hour average $\mathrm{PM}_{2.5}$ concentrations were measured in 11 residential kitchens located in Colchester, England [51]. The reported averages are grouped by housing type, and found to be $56 \mu \mathrm{g} / \mathrm{m}^{3}$ (Coefficient of variation, $C_{v}=71 \%$ ) in student accommodation, $46 \mu \mathrm{g} / \mathrm{m}^{3}\left(C_{v}=71 \%\right)$ in single bedroom flats, and $10 \mu \mathrm{g} / \mathrm{m}^{3}$ $\left(C_{v}=70 \%\right)$ in 2 and 3 bedroom houses. All kitchens were equipped with an extractor fan, and so the measured concentrations are best compared to Ventilation Strategy C (see Table 4), although the fan type and frequency of use were not reported. The measured 24-hour mean concentrations in the student accommodation and single bedroom flats sit between the 25th centile and median, although the measured concentrations in the houses were lower. More recently, measurements of $\mathrm{PM}_{2.5}$ concentrations were recorded over two weeks in kitchens of multiple occupancy student houses [52] in Nottingham, England. Daily mean concentrations are not reported, instead the mean concentration is given for each 7 day monitoring period. During the first week all airflow is assumed to occur solely via infiltration (Strategy A), and the 7-day mean concentrations range between $26.8 \mu \mathrm{g} / \mathrm{m}^{3}\left(C_{v}=400 \%\right)$ and $226.3 \mu \mathrm{g} / \mathrm{m}^{3}\left(C_{v}=375 \%\right)$. The 7 -day mean concentrations in 3 of the 5 houses near or below the 2nd centile for Strategy A. These concentrations suggest that the predictions for Strategy A may overestimate those found in

domestic kitchens. It should be noted that the sample sizes of both studies are small $(N=11$ and $N=5)$ so they cannot be considered representative of the entire English housing stock. A full validation of the model would re- 
quire $\mathrm{PM}_{2.5}$ measurements in a representative sample of English residential kitchens, and will be the subject of future work.

The predictions can also be compared to those of previous modelling studies. Here it is difficult to make direct comparisons because they typically report annual, rather than 24-hour, mean concentrations, and the concentrations are not specifically for kitchens. For example, the annual mean concentration that a member of an average non-smoking household is exposed to is predicted to be $28.4 \mu \mathrm{g} / \mathrm{m}^{3}$ [22]. Furthermore, cooks in domestic kitchens are predicted to be exposed to annual average concentrations of 30$40 \mu \mathrm{g} / \mathrm{m}^{3}$ [23]. Both studies include kitchen extract fans in some dwellings, and also model window opening behaviour [22, 23]. Their predicted concentrations are similar to the 2nd centile for Strategy A (see Table 4) and the 25th centile for Strategy C. This also suggests the current model may overestimate concentrations. However, the annual averages reported in these studies include different cooking schedules for weekends and weekdays, and use a single $\mathrm{PM}_{2.5}$ emission rate of $1.6 \mathrm{mg} / \mathrm{min}$ that accounts for less variability than those used here. Table 2 shows that this value lies within the range applied here, but neither this study, nor those discussed herein, account for extreme emission events, such as those where charring or burning may occur from dirty equipment or as part of the cooking process.

\subsection{Policy, Standards, and Guidelines}

Figure 4 a predicts that over $98 \%$ of English houses are too airtight to provide sufficient infiltration to dilute $\mathrm{PM}_{2.5}$ emissions from cooking sufficiently so that daily mean concentrations in kitchens are below the WHO guideline of $25 \mu \mathrm{g} / \mathrm{m}^{3}$. The EHS [10] records that $47 \%$ of English houses have a fan in 
their kitchen, and so the majority will solely rely on infiltration for dilution during the heating season when windows and vents are closed. In these circumstances, their occupants are likely to be exposed to $\mathrm{PM}_{2.5}$ concentrations that exceed WHO daily guideline.

It is not desirable to increase infiltration because it is positively correlated with heating energy demand. As current policies seek to improve the energy performance of housing stocks, infiltration reduction is a primary method [32]. Therefore, controlled ventilation is required in all kitchens to mitigate against negative impacts on occupant health from cooking. The EHS does not record if fans are wall-mounted or cooker hoods. The difference is important because many cooker hoods recirculate air without extracting it directly outside and do not contain $\mathrm{PM}_{2.5}$ filtration. In future versions of the EHS it would be helpful to record the fan type and whether it exhausts externally. It is also unclear what ventilation rate these fans might provide and so field measurements are required.

Figure 4 shows that the existing domestic kitchen ventilation strategies and airflow rates prescribed in $\mathrm{ADF}$ are predicted to be inadequate in over $88 \%$ of houses when used only during cooking. Continuing to ventilate after cooking ends reduces the daily mean $\mathrm{PM}_{2.5}$ concentration significantly, but they are still above the WHO guideline in $54 \%$ of kitchens. Dobbin et al. [53] found similar benefits of continuing ventilation after emissions end. They measured similar reductions in mean $\mathrm{PM}_{2.5}$ concentration over the monitoring period for keeping the cooker hood on for 15 minutes after cooking as for an increase of almost $50 \mathrm{l} / \mathrm{s}$. This is a similar effect to the reductions seen in Figure 5d, although they are not directly comparable as Dobbin et al. only 
took the average concentration over a single cooking period and the following 15 minutes, rather than a full day with multiple emission periods [53].

The choice of continuing to ventilate for exactly 10 minutes after cooking ends is somewhat arbitrary. However, the optimum duration is a balance between maximizing the rate of concentration reduction and psycho-social factors, such as memory and noise, especially when people also eat in the kitchen after cooking. Therefore, an additional test was run using the data described in Section 2.4 and given in Figure 3, with the addition ventilation period varied between 0 and 60 minutes. The results show a law of diminishing returns where an initially steep decline tends towards an asymptote. Here, the daily average concentration reduces by $58 \%$ for 10 minutes extra ventilation after cooking ends when compared to ventilation just during cooking, but increasing the additional ventilation period to 15 minutes only reduces concentrations by a further $8 \%$ giving a total reduction of $66 \%$. Repeating the evaluation for other kitchens yields a similar pattern, although there is variation in the shape of the curve and the exact time the decrease in concentration begins to plateau. This is likely to be related to the total kitchen air change rate and, therefore, the kitchen volume. Running further simulations could identify the uncertainty in the optimum post-cooking ventilation period from an air quality perspective, but would not reflect human behaviours. Therefore, ventilating for an additional 10 minutes appears appropriate and may also be memorable because it is simple, making it a suitable public health guideline.

The predictions can also be compared against other standards and guidelines for domestic kitchens. For example, ASHRAE 62.2 recommends mini- 
mum extract airflow rates of $150 \mathrm{l} / \mathrm{s}$ or $5 \mathrm{~h}^{-1}$ for enclosed kitchens, or $150 \mathrm{l} / \mathrm{s}$ for non-enclosed kitchens [54]. The current model does not differentiate between enclosed and open plan kitchens, although both are included in the volume distributions given in Figure 2. Figure 5d shows that an extract ventilation rate of $150 \mathrm{l} / \mathrm{s}$ is predicted to keep concentrations below the WHO guideline in $<50 \%$ of new kitchens, when used just during cooking, or $>98 \%$ if they continue to operate for 10 minutes after cooking ends. Alternatively, ASHRAE 62.2 requires an airflow rate of $50 \mathrm{l} / \mathrm{s}$ through a cooker hood. Figure 7 shows that the Example $A$ fan would provide sufficient ventilation in more than $75 \%$ kitchens, and the Example $B$ fan would provide enough ventilation in more than $75 \%$ kitchens if it operates for an additional 10 minutes after cooking. Both example fan performance curves predict required capture efficiencies of over $50 \%$ for an airflow rate of $50 \mathrm{l} / \mathrm{s}$ : $81 \%$ for Example $A$ and $62 \%$ for Example $B$.

European ventilation requirements for residential kitchens vary between countries and are often less specific. For example, the Netherlands Building Decree [55] specifies a capacity of $211 /$ s. Dutch ventilation systems typically have 3 settings: $7 \mathrm{l} / \mathrm{s}$ when the dwelling is unoccupied, 14l/s when occupied, and $21 \mathrm{l} / \mathrm{s}$ during cooking. The current model cannot test this combination because constant and intermittent ventilation strategies are treated as separate scenarios.

European standard EN 16798-1:2019 provides recommended ventilation rates for use in the absence of national standards [56]. Its kitchen extract airflow rate is dependent on the number of main rooms in the dwelling and occupant expectations. For example, for a normal dwelling with 4 main 
rooms, the specified kitchen extract is $35 \mathrm{l} / \mathrm{s}$. However, the standard is unclear whether this is an intermittent or a constant airflow rate, although it does state that the ventilation rate can be halved if there is also a cooker hood present. The prescribed ventilation rate varies with dwelling size and so it is not directly comparable to the predictions made here, which assume the same extract rate for the entire stock. It may be valuable to test the approach given in EN 16798-1 as a method of reducing ventilation rates in smaller dwellings, thereby simultaneously lowering the energy demand and maintaining the level of protection found in larger dwellings. This will be the subject of future work.

The capture efficiency of installed cooker hoods is predicted to play a key role in reducing kitchen $\mathrm{PM}_{2.5}$ concentrations. Measured capture efficiencies have been found to increase with increased flow rate [14, 57, 12], but other factors also affect capture efficiency. They include stove-top coverage, installation height, and kitchen configuration [14, 12]. ASTM standard E308718 gives a procedure to measure capture efficiency for wall mounted cooker hoods [16], but the same procedure is not yet applicable to island hoods or downdraft devices, where the airflow patterns are different [15]. The ASTM procedure also measures with the hood mounted between wall-mounted cabinets [16], which has previously been found to increase the capture efficiency [14. Additionally, Dobbin et al. measured flow rates through installed cooker hoods that were $12-31 \%$ lower than the manufacturer specified rates. For these reasons, manufacturers need to provide installation instructions, and details of how the hood performance may be affected if they are not followed, and to ensure the installed performance matches testing. 
ASTM standard E3087-18 should be cited in standards as the appropriate method for measuring capture efficiency. In the absence of a manufacturer's empirical value, standards should also recommend a punitive values to be used in calculations. A large surveys of the capture efficiencies of every-day cooker hoods is required and could be used to determine appropriate punitive values in the medium term. In the short term, values will require an educated guess.

\section{Conclusions}

This work predicts uncertainty in mean average daily concentrations of $\mathrm{PM}_{2.5}$ emitted by cooking in English kitchens. It is predicted that over $98 \%$ of English houses are too airtight to provide sufficient infiltration to dilute $\mathrm{PM}_{2.5}$ emissions from cooking sufficiently so that daily mean concentrations in kitchens are below the WHO guideline of $25 \mu \mathrm{g} / \mathrm{m}^{3}$. Therefore, controlled ventilation is required in all kitchens to mitigate against cooking related negative health impacts.

The application any of the mechanical ventilation strategies prescribed by England's ADF is predicted to be adequate in less than $12 \%$ of houses when used only during cooking. When the requirements of ASHRAE 62.2 are applied, it is predicted that concentrations are below the WHO guideline in up to $75 \%$ of new kitchens.

When using an intermittent ventilation strategy, continuing to ventilate for a period of time after cooking has finished has a significant effect on the daily mean $\mathrm{PM}_{2.5}$ concentration. However, there are diminishing returns as time increases. A 10 minute period is found to be appropriate. 
When using 10 minutes of additional ventilation after cooking, $\mathrm{PM}_{2.5}$ concentrations are below the WHO guideline in $46 \%$ and $>98 \%$ of kitchens when ADF and ASHRAE 62.2 are applied, respectively. Incorporating the additional 10 minutes of ventilation into the assumptions used to define ventilation strategies and airflow rates prescribed by standards means it must also be a public health guideline. Then, for $75 \%$ of houses to have a daily mean $\mathrm{PM}_{2.5}$ concentration below the WHO guideline, a constant ventilation rate of $61 \mathrm{l} / \mathrm{s}$ or an intermittent ventilation rates $78 \mathrm{l} / \mathrm{s}$ is required.

The most effective ventilation strategy uses a cooker hood located over the hob that captures a proportion of emitted particles and extracts them directly outside. Its ability to do this a function of its capture efficiency and the airflow rate and so both must be specified in standards. Standards should cite ASTM standard E3087-18 as an appropriate capture efficiency test method that cooker hood manufacturers must follow. In the absence of empirical data, punitive values should be specified. For $75 \%$ of houses to have a daily mean $\mathrm{PM}_{2.5}$ concentration below the WHO guideline, a cooker hood with a $50 \%$ capture efficiency requires an airflow rate of $52 \mathrm{l} / \mathrm{s}$ when used during cooking and for 10 minutes afterwards.

\section{Acknowledgements}

The authors are grateful to Barry Cope of the Air Tightness Testing

and Measurement Association (ATTMA) and Jenny Crawley (née Love) of University College London who kindly shared their processed ATTMA air permeability data set [38, 39]. 


\section{Tables}

Table 1: Ventilation Strategies

\begin{tabular}{|c|c|l|}
\hline Strategy & Fan Airflow Rate & Details \\
\hline A & $0 \mathrm{l} / \mathrm{s}$ & Infiltration only \\
B & $13 \mathrm{l} / \mathrm{s}$ & $\begin{array}{l}\text { Constant general extract ventilation at the } \\
\text { high rate from ADF } \\
\text { Intermittent general extract ventilation just } \\
\text { during cooking } \\
\text { C }\end{array}$ \\
Same as $C$ but for an additional 10 minutes \\
after cooking \\
Intermittent extract through a cooker hood, \\
$\eta=50 \%$ just during cooking \\
E
\end{tabular}


Table 2: Mean $(\mu)$ and standard deviation $(\sigma)$ of main meal emission rates and durations [47] and toast 45].

\begin{tabular}{|l|lc|cc|}
\hline Meal Type & \multicolumn{2}{|c|}{ Emission rate $(\mathrm{mg} / \mathrm{min})$} & \multicolumn{2}{|c|}{ Duration (minutes) } \\
& $\mu$ & $\sigma$ & 28 & $\sigma$ \\
\hline Meal 1 (fried chicken, & 0.62 & 0.10 & 28 & 5 \\
fried potatoes, boiled green beans) & & & & \\
Meal 2 (fried chicken, & 0.80 & 0.19 & 28 & 5 \\
boiled potatoes, boiled green beans) & & & 17 & 5 \\
Meal 3 (pasta Bolognese) & 1.9 & 0.74 & & \\
Meal 4 (chicken and vegetable & 3.2 & 0.59 & 3.85 & 0.9 \\
stir-fry) & & & \\
Toast & 0.22 & 0.065 & \\
\hline
\end{tabular}


Table 3: Example Scenario General Inputs

\begin{tabular}{|c|c|c|c|}
\hline Input & \multicolumn{3}{|l|}{ Value } \\
\hline Volume $\left(\mathrm{m}^{3}\right)$ & 22.6 & & \\
\hline Infiltration Rate $\left(\mathrm{h}^{-1}\right)$ & 0.40 & & \\
\hline Deposition Rate $\left(\mathrm{h}^{-1}\right)$ & 0.25 & & \\
\hline Penetration Coefficient (-) & 0.70 & & \\
\hline External Concentration $\left(\mu \mathrm{g} / \mathrm{m}^{3}\right)$ & 12.8 & & \\
\hline Initial Concentration $\left(\mu \mathrm{g} / \mathrm{m}^{3}\right)$ & & & \\
\hline Number of cooking periods & 3 & & \\
\hline Emission number & 1 & 2 & 3 \\
\hline Meal Type & Toast & Meal 1 & Meal 3 \\
\hline Emission Rate (mg/min) & 1.22 & 2.70 & 12.4 \\
\hline Duration (minutes) & 3.5 & 28.1 & 20.8 \\
\hline Post cooking interval (hours) & 4.6 & 9.1 & \\
\hline
\end{tabular}


Table 4: Predicted 24-hour mean average concentrations $\left(\mu \mathrm{g} / \mathrm{m}^{3}\right)$ in English kitchens for all ventilation strategies

\begin{tabular}{|c|c|c|c|c|c|c|}
\hline \multirow{2}{*}{$\begin{array}{l}\text { Centile/ } \\
\text { Statistic }\end{array}$} & \multicolumn{4}{|c|}{ Strategy (see Table 1} & \multicolumn{2}{|c|}{ for details) } \\
\hline & A & $\mathrm{B}$ & $\mathrm{C}$ & $\mathrm{D}$ & $\mathrm{E}$ & $\mathrm{F}$ \\
\hline \multicolumn{7}{|c|}{ Existing Stock } \\
\hline $2 \%$ & 39.3 & 25.8 & 21.3 & 12.5 & 17.3 & 13.5 \\
\hline $25 \%$ & 111 & 42.7 & 39.6 & 19.3 & 33.0 & 22.1 \\
\hline $50 \%$ & 186 & 58.3 & 60.5 & 26.1 & 50.5 & 30.8 \\
\hline $75 \%$ & 321 & 75.8 & 89.4 & 34.8 & 75.2 & 42.1 \\
\hline $98 \%$ & 867 & 117 & 187 & 64.2 & 165 & 81.4 \\
\hline$\mu$ & 250 & 61.2 & 70.3 & 28.8 & 59.5 & 34.4 \\
\hline$\sigma$ & 216 & 23.4 & 42.4 & 13.2 & 37.2 & 17.0 \\
\hline \multicolumn{7}{|c|}{ New Houses } \\
\hline $2 \%$ & 40.5 & 24.9 & 22.3 & 12.5 & 16.8 & 13.5 \\
\hline $25 \%$ & 118 & 42.0 & 43.8 & 20.1 & 35.2 & 22.6 \\
\hline $50 \%$ & 211 & 57.7 & 68.2 & 27.8 & 54.6 & 32.2 \\
\hline $75 \%$ & 375 & 75.7 & 100 & 38.1 & 83.6 & 44.9 \\
\hline $98 \%$ & 1080 & 117 & 226 & 74.9 & 190 & 93.6 \\
\hline$\mu$ & 294 & 60.9 & 79.4 & 31.3 & 65.8 & 36.7 \\
\hline$\sigma$ & 287 & 23.7 & 50.5 & 15.8 & 44.1 & 20.1 \\
\hline
\end{tabular}


Table 5: Required general extract ventilation rates

\begin{tabular}{|c|c|c|c|c|c|c|}
\hline \multirow[b]{3}{*}{ Centile } & \multirow{2}{*}{\multicolumn{2}{|c|}{$\begin{array}{l}\text { Constant } \\
\text { Ventilation }\end{array}$}} & \multicolumn{4}{|c|}{ Intermittent Ventilation } \\
\hline & & & \multicolumn{2}{|c|}{ During Cooking } & \multicolumn{2}{|c|}{ Plus 10 minutes } \\
\hline & $1 / \mathrm{s}$ & $\mathrm{h}^{-1}$ & $1 / \mathrm{s}$ & $\mathrm{h}^{-1}$ & $1 / \mathrm{s}$ & $h^{-1}$ \\
\hline \multicolumn{7}{|c|}{ Existing stock } \\
\hline $2 \%$ & 14 & 1.2 & 42 & 3.8 & 25 & 2.4 \\
\hline $25 \%$ & 30 & 4.0 & 114 & 16 & 47 & 6.8 \\
\hline $50 \%$ & 46 & 6.9 & 189 & 29 & 62 & 9.8 \\
\hline $75 \%$ & 61 & 11 & 289 & 50 & 78 & 13 \\
\hline $98 \%$ & 97 & 24 & 627 & 131 & 119 & 22 \\
\hline \multicolumn{7}{|c|}{ New houses } \\
\hline $2 \%$ & 13 & 0.79 & 48 & 3.4 & 27 & 2.0 \\
\hline $25 \%$ & 30 & 3.3 & 129 & 16 & 49 & 6.2 \\
\hline $50 \%$ & 45 & 6.4 & 216 & 30 & 65 & 9.5 \\
\hline $75 \%$ & 62 & 11 & 323 & 54 & 83 & 13 \\
\hline $98 \%$ & 96 & 25 & 726 & 154 & 137 & 23 \\
\hline
\end{tabular}


Table 6: Sensitivity of $\overline{C(t)}$ to model inputs. 1 is the highest rank.

\begin{tabular}{|c|c|c|c|c|c|c|c|c|c|c|}
\hline Input $\backslash$ Test & $S_{K e n d}$ & $S_{\text {Pear }}$ & $S_{\text {Spear }}$ & $S_{\text {regress }}$ & $S_{\text {rankreg }}$ & $S_{K o l m}$ & $S_{\text {Krusk } 2}$ & $S_{\text {Krusk5 }}$ & $S_{\text {Krusk10 }}$ & $S_{K r u s k 20}$ \\
\hline$\Sigma g$ & 1 & 1 & 1 & 1 & 1 & 1 & 1 & 1 & 1 & 1 \\
\hline$V$ & 2 & 3 & 2 & 3 & 2 & 2 & 2 & 2 & 2 & 2 \\
\hline$\lambda_{N}$ & 3 & 5 & 3 & 5 & 3 & 3 & 3 & 3 & 3 & 3 \\
\hline$k$ & 4 & 4 & 4 & 4 & 4 & 4 & 4 & $4^{*}$ & 5 & 5 \\
\hline$C(0)$ & 5 & 2 & 5 & 2 & 5 & 5 & 5 & 5 & 4 & 4 \\
\hline$C_{a}$ & $6^{*}$ & 6 & $6^{*}$ & 6 & 6 & $8^{*}$ & $7^{*}$ & $8^{*}$ & $7^{*}$ & $6^{*}$ \\
\hline$(\overline{\Delta t})$ & $7^{*}$ & $8^{*}$ & $7 *$ & 8 & 7 & 6 & $6^{*}$ & $7^{*}$ & $8^{*}$ & $8^{*}$ \\
\hline$P$ & $8^{*}$ & $7^{*}$ & $8^{*}$ & 7 & 8 & $7^{*}$ & $8^{*}$ & $6^{*}$ & $6^{*}$ & $7^{*}$ \\
\hline
\end{tabular}

* indicates tests which were non-significant at the $p \leq 0.05$ significance level 


\section{Figures}

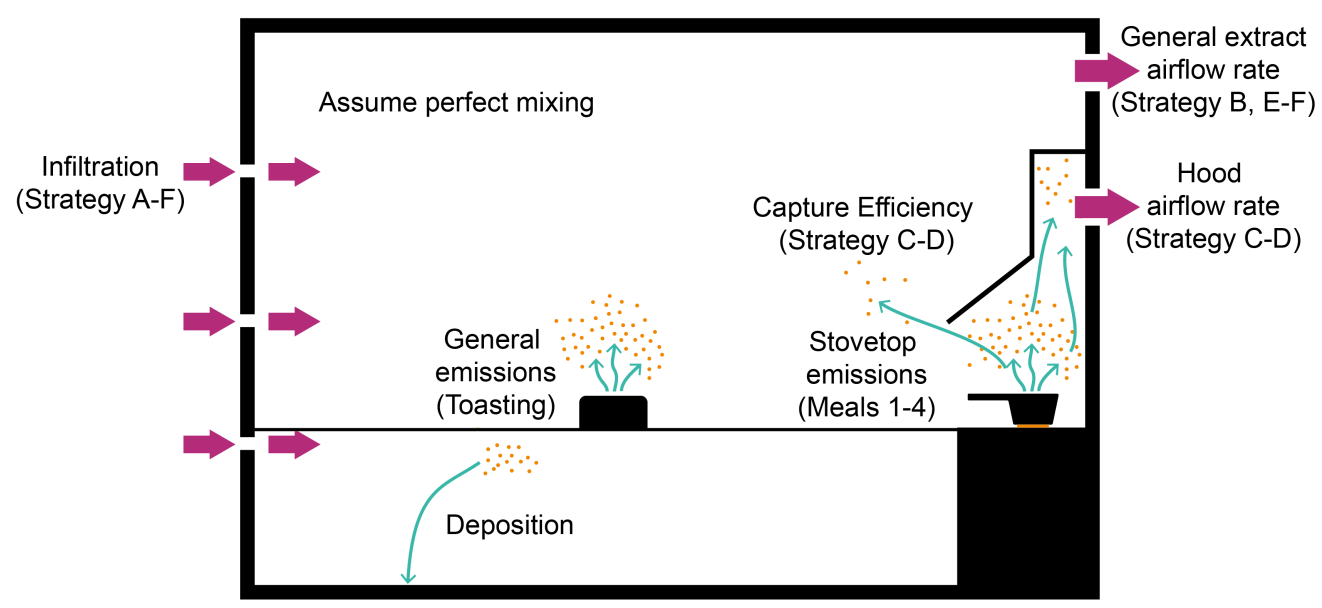

Figure 1: Kitchen ventilation strategies and model inputs. 

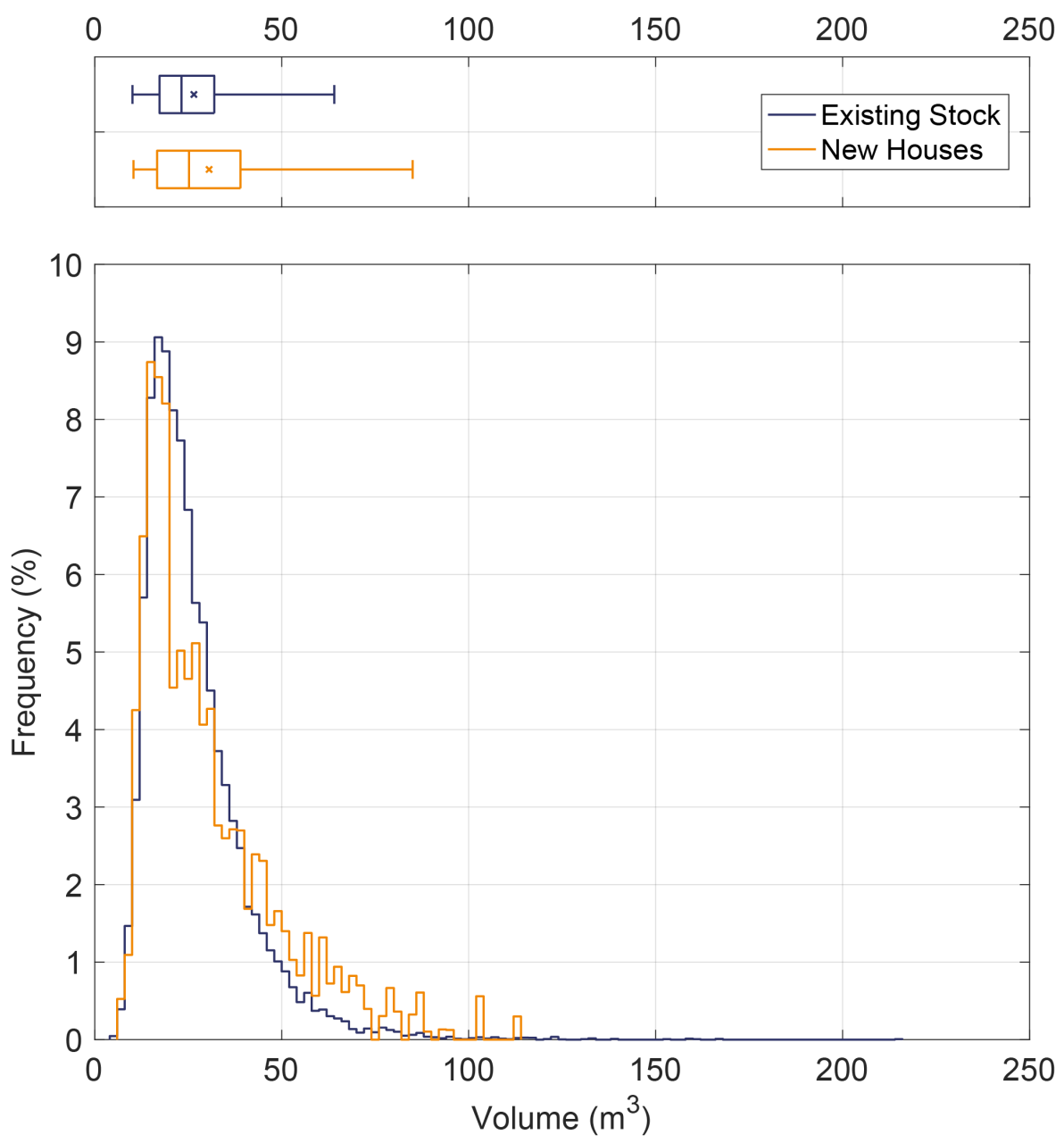

Figure 2: Distributions of English kitchen volumes [10. 


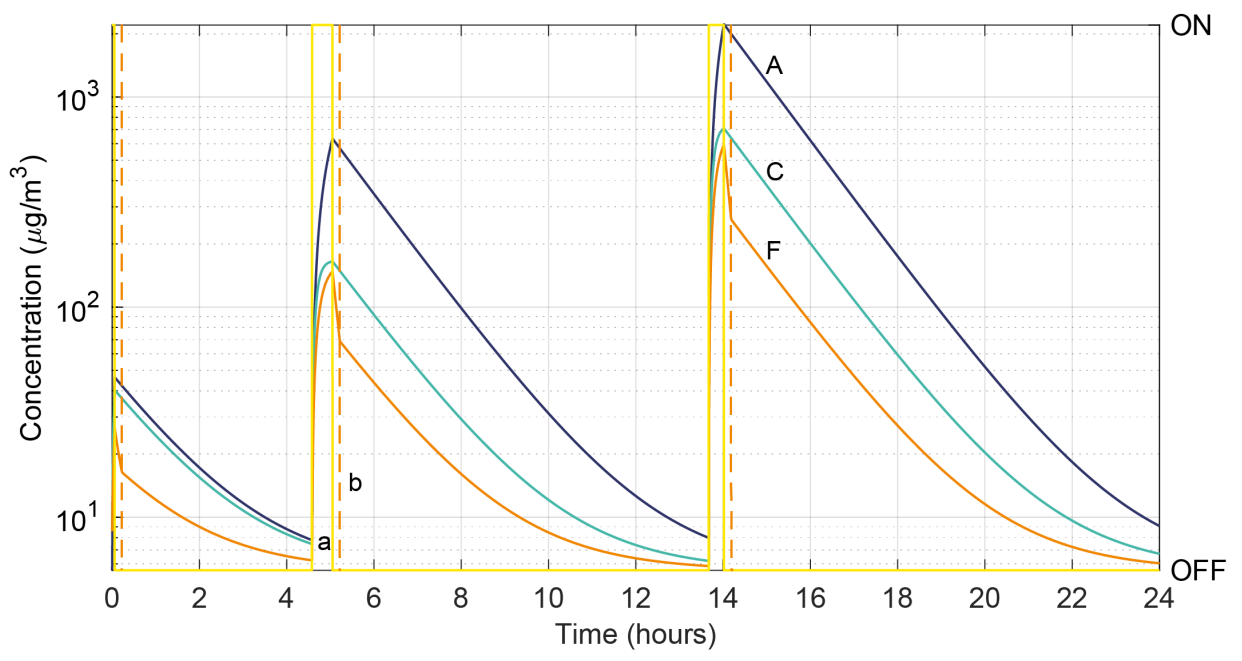

Figure 3: Example Scenarios

A (navy), infiltration only ; C (teal), 60l/s general extract during cooking;

F (orange), 30l/s extract through cooker hood with $\eta=50 \%$ during cooking plus 10 minutes after; a (yellow), source emission function; b (orange dashed), marks 10 minutes after the end of cooking. 


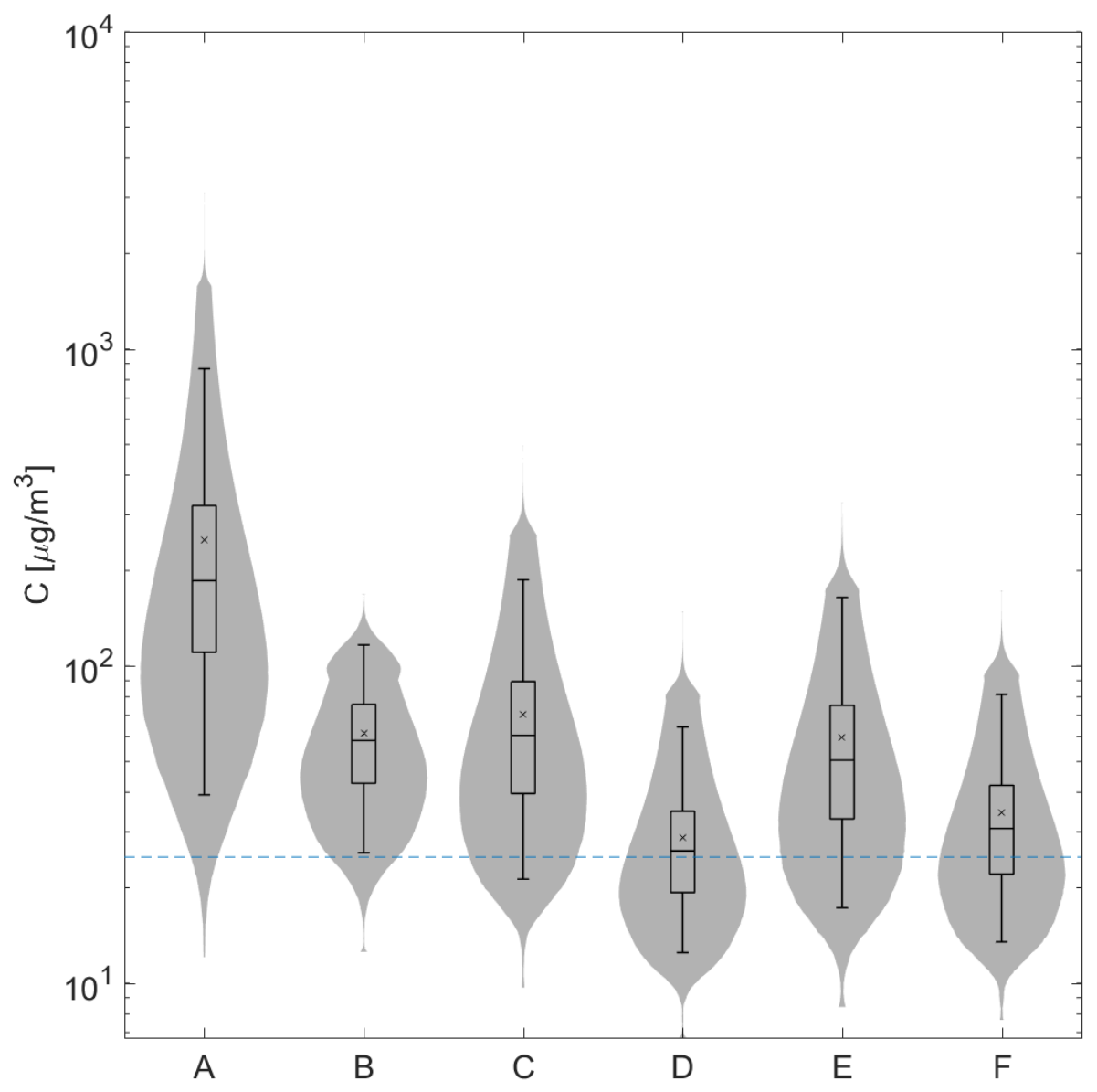

(a) Existing houses 


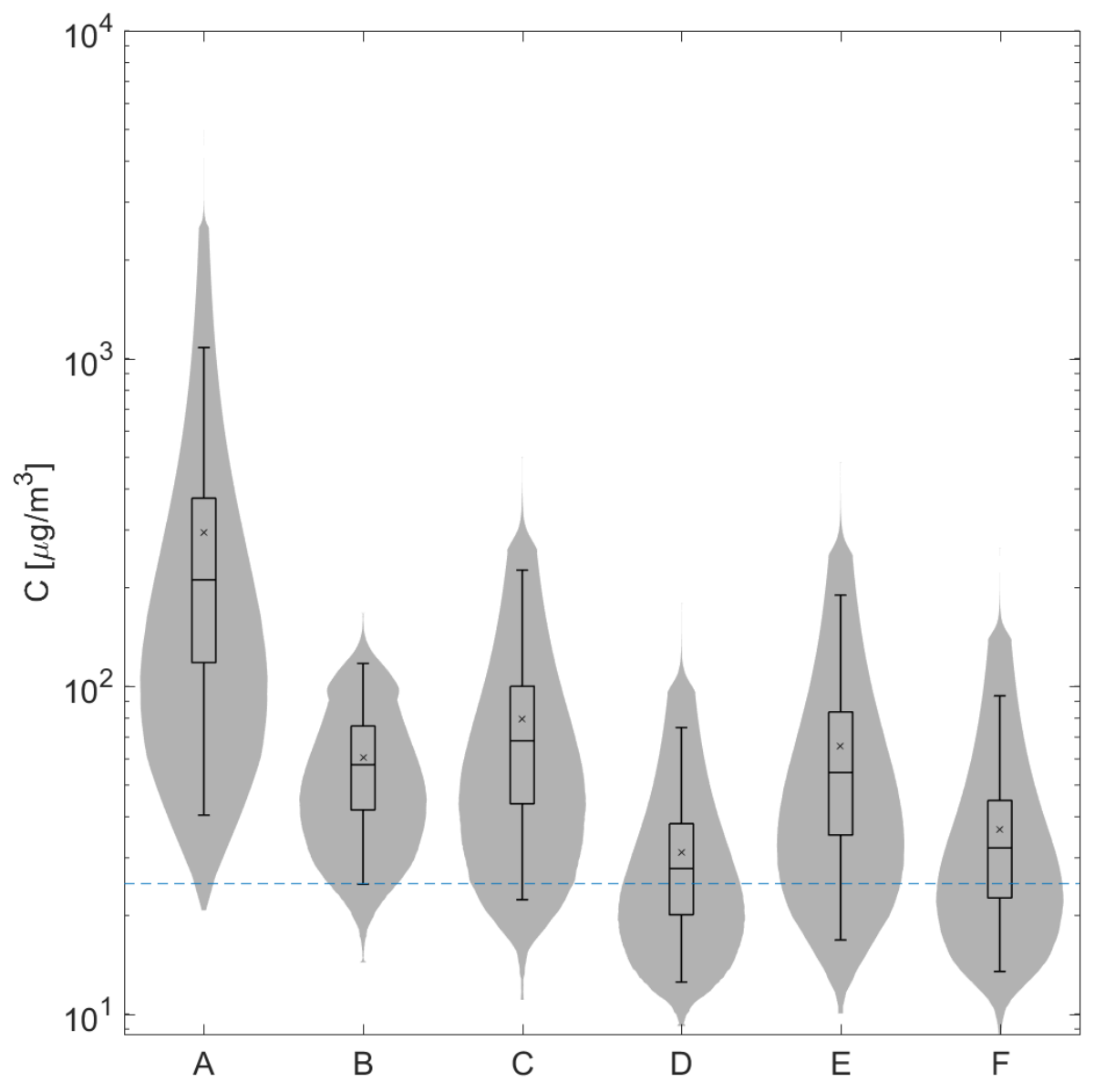

(b) New houses

Figure 4: Predicted distributions of $\mathrm{PM}_{2.5}$ concentration for existing building regulation ventilation strategies. 


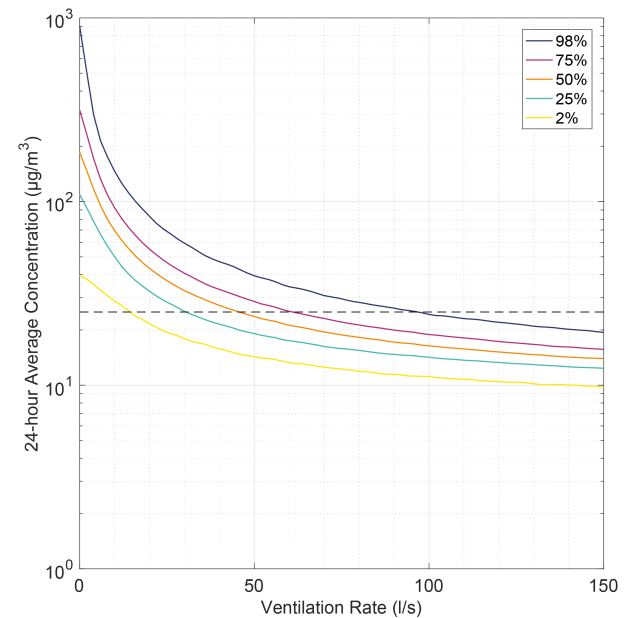

(a) Constant Ventilation

Existing stock

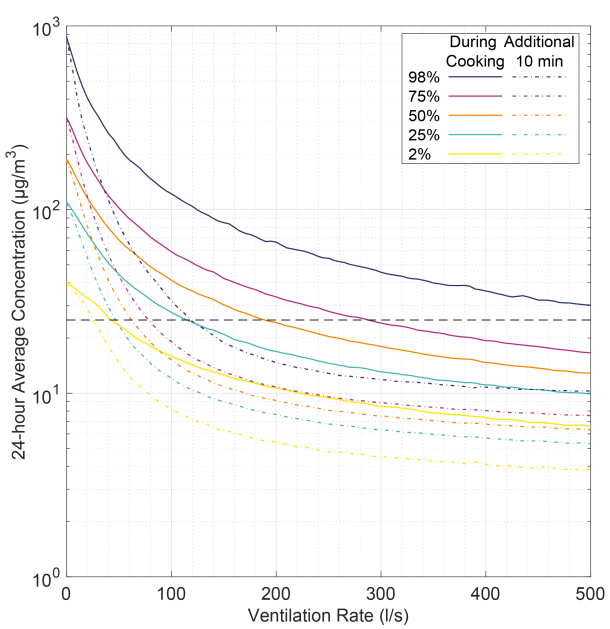

(c) Intermittent ventilation

Existing stock

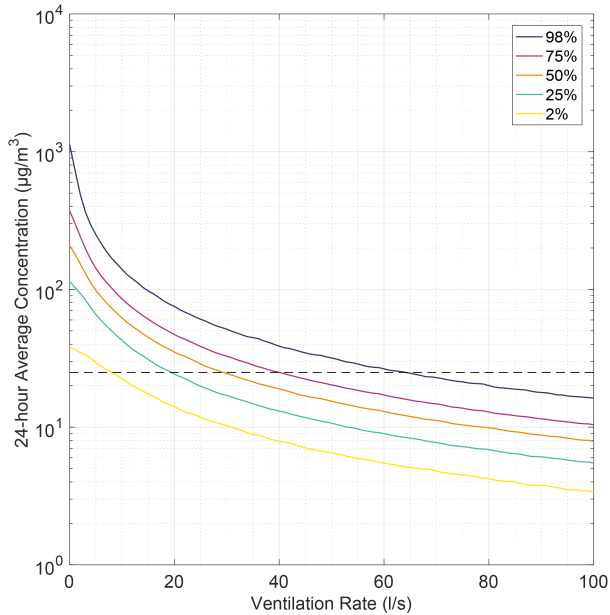

(b) Constant ventilation

New houses

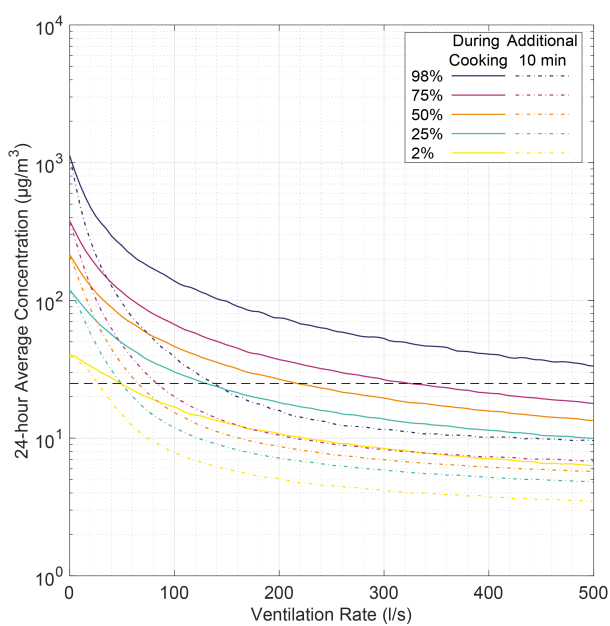

(d) Intermittent ventilation

New houses

Figure 5: Predicted concentrations for general extract ventilation. 


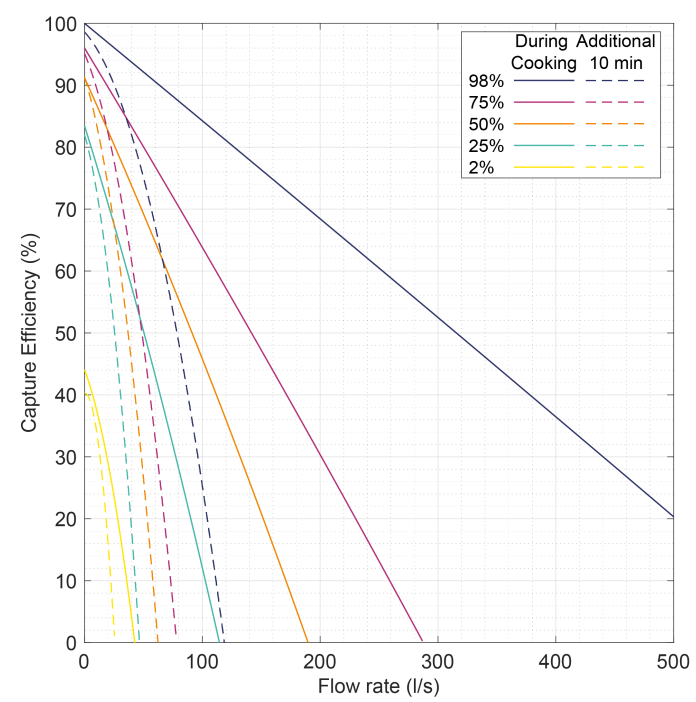

(a) Existing stock

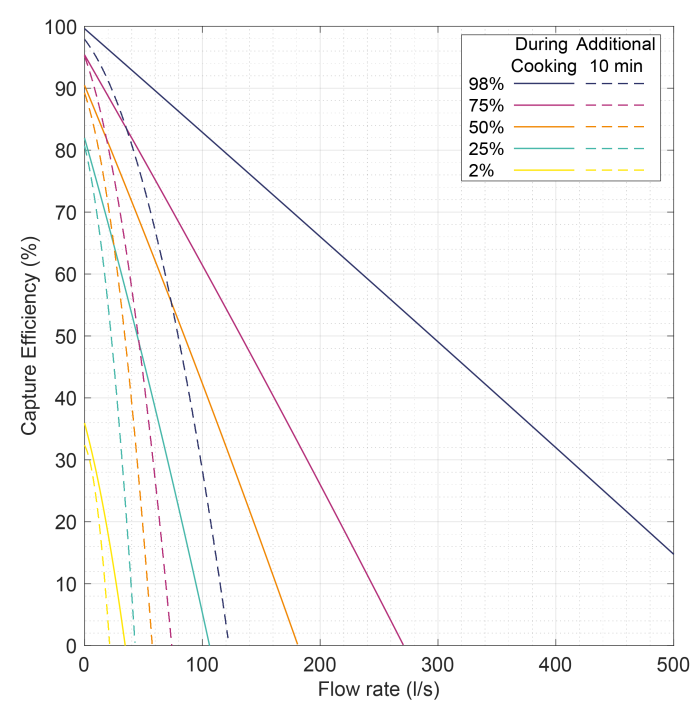

(b) New houses

Figure 6: Required combinations of airflow rate and capture efficiency. 


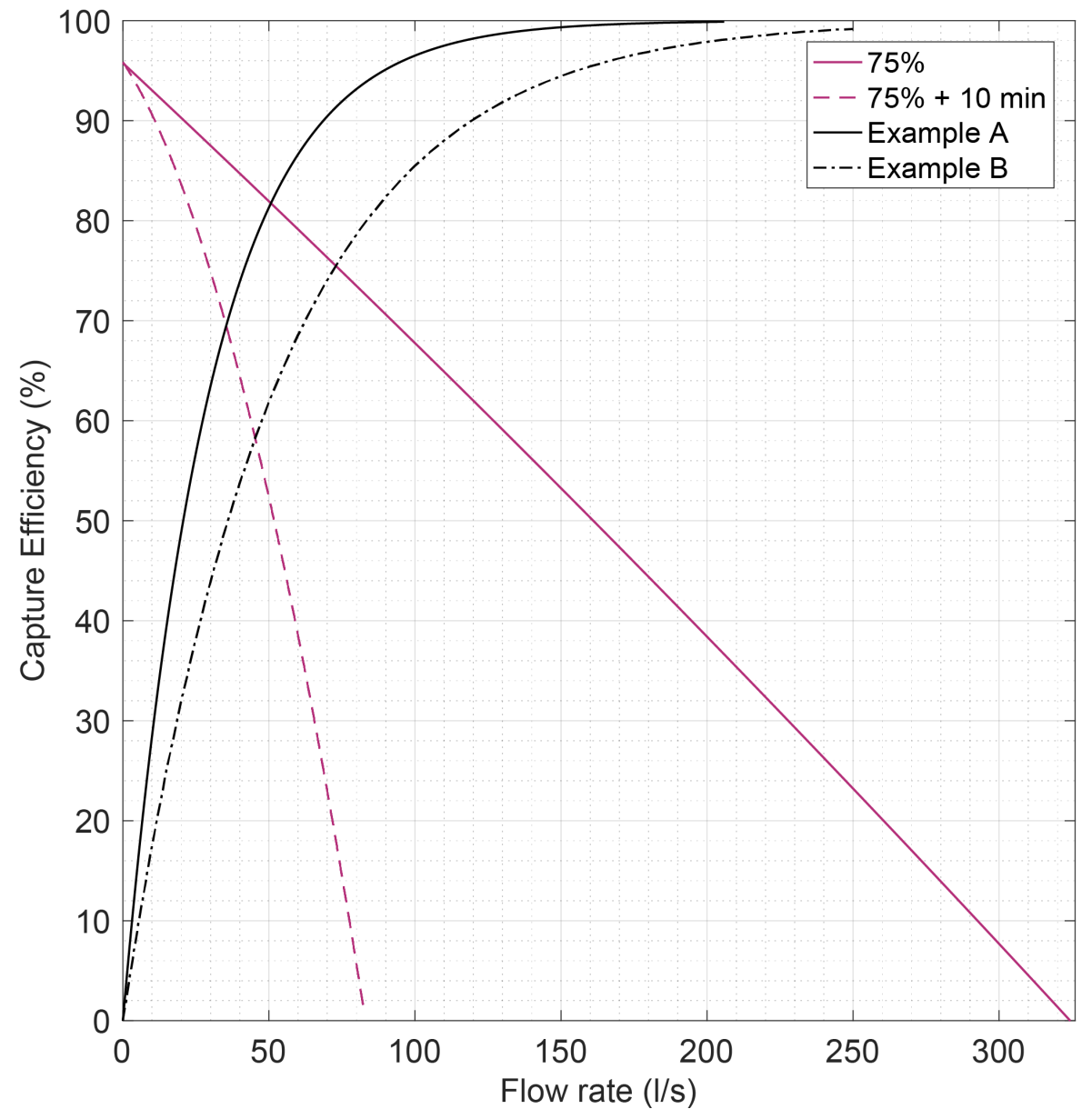

Figure 7: Measured cooker hood performance with 75th centile airflow rate-capture efficiency curves for new houses 


\section{References}

[1] C. A. Pope, D. W. Dockery, Health effects of fine particulate air pollution: Lines that connect, Journal of the Air Waste Management Association 56 (6) 709-742. doi:10.1080/10473289.2006. 10464485 .

[2] J. Lewtas, Air pollution combustion emissions: Characterization of causative agents and mechanisms associated with cancer, reproductive, and cardiovascular effects, Mutation Research/Reviews in Mutation Research 636 (13) 95-133. doi:10.1016/j.mrrev.2007. 08.003 .

[3] COMEAP, COMEAP: mortality effects of long term exposure to particulate air pollution in the uk (2010).

URL WWW.gov.uk/government/publications/

comeap-mortality-effects-of-long-term-exposure-to-particulate-air-polluti

[4] COMEAP, Effects of long-term exposure to ambient air pollution on cardiovascular morbidity: mechanistic evidence. (2018).

URL WWW.gov.uk/government/publications/ air-pollution-and-cardiovascular-disease-mechanistic-evidence

[5] Air quality standards regulations (2010).

URL http://www.legislation.gov.uk/uksi/2010/1001/ resources

[6] D. Lader, S. Short, J. Gershuny, The time use survey, 2005: how we spend our time, Report, Office for National Statistics (2006). 
[7] C. Dimitroulopoulou, M. R. Ashmore, A. C. Terry, Use of population exposure frequency distributions to simulate effects of policy interventions on $\mathrm{NO}_{2}$ exposure, Atmospheric Environment 150 (2017) 1-14. doi:10.1016/j.atmosenv.2016.11.028.

[8] T. Salthammer, Critical evaluation of approaches in setting indoor air quality guidelines and reference values, Chemosphere 82 (11) 1507-1517. doi:10.1016/j.chemosphere.2010.11.023.

[9] A. Afshari, U. Matson, L. E. Ekberg, Characterization of indoor sources of fine and ultrafine particles: a study conducted in a full-scale chamber, Indoor Air 15 (2) 141-50. doi:10.1111/j. $1600-0668.2005 .00332 . x$.

[10] Department for Communities and Local Government, English housing survey, 2009: Housing stock data (2017). doi:10.5255/ UKDA-SN-6804-3.

URL http://doi .org/10.5255/UKDA-SN-6804-3

[11] H.M. Government, The Building Regulations 2000. Approved Document F, Ventilation, 2010th Edition, Ventilation, Norwich : TSO, Norwich, 2010.

[12] M. M. Lunden, W. W. Delp, B. C. Singer, Capture efficiency of cooking-related fine and ultrafine particles by residential exhaust hoods, Indoor Air 25 (2015) 4558.

[13] D. Rim, L. Wallace, S. Nabinger, A. Persily, Reduction of exposure to ultrafine particles by kitchen exhaust hoods: The effects of ex- 
haust flow rates, particle size, and burner position, Science of The Total Environment 432 350-356. doi:https://doi.org/10.1016/ j.scitotenv.2012.06.015.

[14] B. C. Singer, W. W. Delp, P. N. Price, M. G. Apte, Performance of installed cooking exhaust devices, Indoor Air 22 (3) 224-34. doi: $10.1111 / j .1600-0668.2011 .00756 . x$.

[15] Y.-S. Kim, I. S. Walker, W. W. Delp, Development of a standard capture efficiency test method for residential kitchen ventilation, Science and Technology for the Built Environment 24 (2) 176-187. doi:10.1080/23744731.2017.1416171.

[16] ASTM, Measuring capture efficiency of domestic range hoods, Report, American Society for Testing and Materials (2018).

[17] WHO, WHO air quality guidelines for particulate matter, ozone, nitrogen dioxide and sulfur dioxide, Report, Word Health Organization (2005).

[18] WHO, WHO guidelines for indoor air quality: selected pollutants, Report, Word Health Organization (2010).

[19] NAAQS table (2015).

URL https://www.epa.gov/criteria-air-pollutants/ naaqs-table

[20] IWBI, The WELL Building Standard, 1st Edition, International WELL Building Institute (IWBI), Delos Living LLC, New York, USA, 2016. 
[21] P. Das, C. Shrubsole, B. Jones, I. Hamilton, Z. Chalabi, M. Davies, A. Mavrogianni, J. Taylor, Using probabilistic sampling-based sensitivity analyses for indoor air quality modelling, Building and Environment 78 (2014) 171-182. doi:10.1016/j.buildenv.2014. 04.017.

[22] C. Shrubsole, I. Ridley, P. Biddulph, J. Milner, S. Vardoulakis, M. Ucci, P. Wilkinson, Z. Chalabi, M. Davies, Indoor $\mathrm{PM}_{2.5}$ exposure in london's domestic stock: Modelling current and future exposures following energy efficient refurbishment, Atmospheric Environment 62 (0) 336-343. doi:10.1016/j .atmosenv .2012.08.047.

[23] C. Shrubsole, J. Taylor, P. Das, I. G. Hamilton, E. Oikonomou, M. Davies, Impacts of energy efficiency retrofitting measures on indoor $\mathrm{PM}_{2.5}$ concentrations across different income groups in england: a modelling study, Advances in Building Energy Research 1-15doi:10.1080/17512549.2015.1014844.

[24] J. Milner, C. Shrubsole, P. Das, B. Jones, I. Ridley, Z. Chalabi, I. Hamilton, B. Armstrong, M. Davies, P. Wilkinson, Home energy efficiency and radon related risk of lung cancer: modelling study, BMJ 348 (2014). doi:10.1136/bmj.f7493.

[25] I. Hamilton, J. Milner, Z. Chalabi, P. Das, B. Jones, C. Shrubsole, M. Davies, P. Wilkinson, Health effects of home energy efficiency interventions in england: a modelling study, BMJ Open 5 (4). doi : 10.1136/bmjopen-2014-007298. 
[26] C. Dimitroulopoulou, M. R. Ashmore, M. A. Byrne, Modelling the contribution of passive smoking to exposure to $\mathrm{PM}_{10}$ in uk homes, Indoor and Built Environment 10 (3-4) (2001) 209-213. doi:10. $1159 / 000049238$.

[27] M. T. R. Hill, C. Dimitroulopoulou, M. R. Ashmore, K. Batty, Measurement and modelling of short-term variations in particle concentrations in uk homes, Indoor and Built Environment 10 (3-4) 132-137. doi:10.1177/1420326X0101000303.

[28] C. Dimitroulopoulou, M. Ashmore, M. Hill, M. Byrne, R. Kinnersley, INDAIR: A probabilistic model of indoor air pollution in uk homes, Atmospheric Environment 40 (33) (2006) 6362 - 6379. doi:10.1016/j.atmosenv.2006.05.047.

[29] C. O'Leary, B. Jones, I. Hall, Estimated distributions of $\mathrm{PM}_{2.5}$ concentrations in the kitchens of the english housing stock for infiltration and mechanical ventilation scenarios, in: 39th Air Infiltration and Ventilation Centre Conference, Vol. 1, Antibes Juan-Les-Pins, France, 2018, pp. 1090-1099.

[30] W. Ott, A. C. Steinemann, L. A. Wallace, Exposure analysis / edited by Wayne R. Ott, Anne C. Steinemann, Lance A. Wallace, Boca Raton London : CRC Press, Boca Raton London, 2007.

[31] P. J. Dacunto, K.-C. Cheng, V. Acevedo-Bolton, R.-T. Jiang, N. E. Klepeis, J. L. Repace, W. R. Ott, L. M. Hildemann, Real-time particle monitor calibration factors and $\mathrm{PM}_{2.5}$ emission factors for 
multiple indoor sources, Environmental Science: Processes Impacts 15 (8) (2013) 1511-1519. doi:10.1039/C3EM00209H.

[32] B. Jones, P. Das, Z. Chalabi, M. Davies, I. Hamilton, R. Lowe, A. Mavrogianni, D. Robinson, J. Taylor, Assessing uncertainty in housing stock infiltration rates andassociated heat loss: English and uk case studies, Building and Environment 92 644-656. doi: 10.1016/j.buildenv.2015.05.033.

[33] M. Lyberg, Basic air infiltration, Building and Environment 32 (2) 95-100. doi:10.1016/s0360-1323(96) 00048-0.

[34] R. Lowe, Ventilation strategy, energy use and $\mathrm{CO}_{2}$ emissions in dwellings - a theoretical approach, Building Services Engineering Research and Technology 21 (3) 179-185. doi:10.1177/ 014362440002100306 .

[35] B. Jones, R. Lowe, Predicting the optimum air permeability of a stock of detached english dwellings, in: 35th Air Infiltration and Ventilation Centre Conference, Vol. 1, 2014, pp. 575-586.

[36] B. Jones, P. Das, Z. Chalabi, M. Davies, I. Hamilton, R. Lowe, J. Milner, I. Ridley, C. Shrubsole, P. Wilkinson, The effect of party wall permeability on estimations of infiltration from air leakage, International Journal of Ventilation 12 (1) (2013) 17-29.

[37] R. Stephen, Airtightness in uk dwellings: Bre's test results and their significance, Report, Building Research Establishment (1998). 
[38] J. Love, J. Wingfield, A. Z. P. Smith, P. Biddulph, T. Oreszczyn, R. Lowe, C. A. Elwell, hitting the target and missing the point: Analysis of air permeability data for new uk dwellings and what it reveals about the testing procedure, Energy and Buildings 155 (Supplement C) 88-97. doi:10.1016/j.enbuild.2017.09. 013.

[39] J. Crawley, J. Wingfield, C. Elwell, The relationship between airtightness and ventilation in new uk dwellings, Building Services Engineering Research and Technology (2018) 0143624418822199doi: 10.1177/0143624418822199. URL https://doi .org/10.1177/0143624418822199

[40] L. Palmiter, T. Bond, Impact of mechanical systems of ventilation and infiltration in homes, in: 12th Air Infiltration and Ventilation Center Conference, 1991, pp. 285-295.

[41] N. Hurel, M. Sherman, I. S. Walker, Simplified methods for combining natural and mechanical ventilation, in: 36th Air Infiltration and Ventilation Center Conference, 2015, pp. 840-849.

[42] S. V. Hering, M. M. Lunden, T. L. Thatcher, T. W. Kirchstetter, N. J. Brown, Using regional data and building leakage to assess indoor concentrations of particles of outdoor origin, Aerosol Science and Technology 41 (7) 639-654. doi:10.1080/ 02786820701368026 .

[43] J. Taylor, C. Shrubsole, P. Symonds, I. Mackenzie, M. Davies, 
Application of an indoor air pollution metamodel to a spatiallydistributed housing stock, Science of The Total Environment 667 (2019) 390-399. doi:10.1016/j.scitotenv.2019.02.341.

[44] H. Ozkaynak, J. Xue, J. Spengler, L. Wallace, E. Pellizzari, P. Jenkins, Personal exposure to airborne particles and metals: results from the particle team study in riverside, california, Journal of exposure analysis and environmental epidemiology 6 (1) 57-78.

[45] C. O'Leary, B. Jones, A method to measure emission rates of $\mathrm{PM}_{2.5} \mathrm{~S}$ from cooking, in: 38th Air Infiltration and Ventilation Centre Conference, Vol. 1, Nottingham, UK, 2017.

[46] B. Jones, G. Phillips, C. O'Leary, C. Molina, I. Hall, M. Sherman, Diagnostic barriers to using $\mathrm{PM}_{2.5}$ concentrations as metrics of indoor air quality, in: 39th Air Infiltration and Ventilation Centre Conference, Vol. 1, Antibes Juan-Les-Pins, France, 2018, pp. 404413.

[47] C. O'Leary, Y. de Kluizenaar, P. Jacobs, W. Borsboom, I. Hall, B. Jones, Investigating measurements of fine particle (PM2.5) emissions from the cooking of meals and mitigating exposure using a cooker hood, Indoor Air 29 (3) 423-438. doi:10.1111/ina.12542.

[48] P. Jacobs, Openbaar eindrapport ventkook ventilatiesysteem met goed kookafzuiging, Report, Delft: TNO (2018 2018).

URL https://repository.tudelft.nl/view/tno/uuid: d69350eb-4520-41f8-b5ff-7be8b92fab31 
[49] I. Walker, J. Stratton, W. Delp, M. Sherman, Development of a tracer gas capture efficiency test method for residential kitchen ventilation, Report (2016).

URL https://eta.lbl.gov/sites/all/files/publications/ iain_walker_-_development_of_a_tracer_gas_capture_ efficiency_test_method_for_residential_kitchen_ ventilation.pdf

[50] M. Liddament, Occupant impact on ventilation, Report, AIVC (2001).

[51] Z. A. Nasir, I. Colbeck, Particulate pollution in different housing types in a uk suburban location, Science of The Total Environment 445-446 165-176. doi:10.1016/j.scitotenv.2012.12.042.

[52] C. O'Leary, B. Jones, I. Hall, An intervention study of $\mathrm{PM}_{2.5}$ concentrations measured in domestic kitchens, in: 39th Air Infiltration and Ventilation Centre Conference, Vol. 1, Antibes Juan-Les-Pins, France, 2018, pp. 1090-1099.

[53] N. A. Dobbin, L. Sun, L. Wallace, R. Kulka, H. You, T. Shin, D. Aubin, M. St-Jean, B. C. Singer, The benefit of kitchen exhaust fan use after cooking - an experimental assessment, Building and Environment 135 (2018) 286-296. doi:10.1016/j.buildenv. 2018.02.039.

[54] ASHRAE, ANSI/ASHRAE standard 62.2 - ventilation and acceptable indoor air quality in residential buildings, Report, The Amer- 
ican Society of Heating, Refrigerating and Air-Conditioning Engineers (2016).

[55] BRIS, Bouwbesluit 2012 (Dutch Building Code), [in Dutch] (2012). URL www . bouwbesluitonline.nl

[56] BSI, BS EN 16798-1:2019 energy performance of buildings. ventilation for buildings. indoor environmental input parameters for design and assessment of energy performance of buildings addressing indoor air quality, thermal environment, lighting and acoustics. module m1-6, Report (08 May 2019 2019).

URL https://shop.bsigroup.com/ProductDetail/?pid= 000000000030297474

[57] W. W. Delp, B. C. Singer, Performance assessment of U.S. residential cooking exhaust hoods, Environmental Science Technology 46 (11) (2012) 6167-6173. doi:10.1021/es3001079. 